\title{
HISTÓRIA DE UMA FOTO E FOTOS QUE CONTAM HISTÓRIAS
}

\author{
The story of a photograph and photographs that tell stories
}

Ondina Fachel Leal ${ }^{1}$

Luiz Eduardo Robinson Achutti ${ }^{2}$

http://dx.doi.org/10.52641/cadcaj.v7i1.659

Homenagem a Mauro Guilherme Pinheiro Koury, in memoriam.

Resumo: Esse artigo é uma homenagem a Mauro Guilherme Pinheiro Koury (in memoriam), que soube compartilhar com todos nós seu conhecimento sobre emoções e sobre imagens. O texto busca estabelecer um paralelo entre duas sequências de fotos de Achutti. Toma dois conjuntos de imagens, ou duas narrativas a respeito de processos de mobilização e protesto de mulheres que ocorrem em um intervalo de mais de três décadas, em contextos históricos distintos, ambos eventos se deram no mesmo cenário, a Casa de Estudantes da UFRGS em Porto Alegre.

Palavras-chaves: Fotografia, Fotoetnografia, Imagens.

Abstract: This article is a tribute to Mauro Guilherme Pinheiro Koury (in memoriam), who knew so much about both emotions and images. This article establishes a parallel between two sequences of Achutti's photos. It takes two sets of images, or two narratives about two events of women's mobilization and protest that happened in a time gap of more than three decades, in different historical contexts, both took place in the same setting, the UFRGS Student House in Porto Alegre. Keywords: Photography, Photoethnography, Images.

\section{DOR, EMOÇÃO E IMAGENS}

"Não é só o receio da morte, de fato ela está presente e as pessoas se sentem no meio de um cerco cada vez mais apertado à sua volta".

Mauro Koury, Tempos de Pandemia (2020) p. 19.

\footnotetext{
${ }^{1}$ Ondina Fachel Leal é Doutora em Antropologia, University of California, Berkeley (1989);

Professora Titular Universidade Federal do Rio Grande do Sul (aposentada). E-mail:

ofachelleal@gmail.com.

${ }^{2}$ Luiz Eduardo Robinson Achutti é Doutor em Antropologia, Université Paris VII, Denis-Diderot (2002); Professor Titular Universidade Federal do Rio Grande do Sul (UFRGS). E-mail: robison.achutti@gmail.com. Orcid: 0000-0002-2721-6659.
} 
É quase metade do ano de 2021, nosso segundo ano da praga que assola o mundo, a pandemia Covid-19. Para nós, nesse canto do mundo, o Brasil, outras pragas começaram antes, pois já se vão cinco anos que um houve um golpe e a presidente eleita foi destituída por alegações das quais já foi inocentada. Através de fragmentados textos virtuais - já que o isolamento sanitário não permite o encontro face a face - Achutti e eu conversávamos sobre essas coisas: sobre o isolamento, sobre aquela mistura de dor, tristeza e raiva que a situação de pandemia e de descaso e irresponsabilidade governamental nos impunha, enfim, conversávamos sobre nossas próprias emoções presos e sendo levados por um potente redemoinho de eventos terríveis do qual não conseguíamos sair. Comentamos sobre o trabalho recente que um amigo comum, Mauro Koury, tinha recém-publicado, Tempos de Pandemia (2020), a imagem de redemoinho de terror de onde não estamos conseguindo sair está presente em seu trabalho sobre a epidemia de Covid 19. Koury menciona esse torvelinho de emoções no enfrentamento de uma crise sanitária que vem junto com outra crise, talvez mais drástica ainda, uma crise política e de falência moral, onde o sofrimento leva à desesperança social, "do desrespeito para com a dor do outro e do terror das mortes que se acumulam". (Koury 2020, p. 15-17). O torvelinho de terror, impiedoso, levou também nosso grande Mauro Guilherme Pinheiro Koury. Deixou suas palavras, uma ausência insubstituível nas ciências sociais e muita, muita dor.

Koury sempre foi inovador na abordagem de novos temas e em abrir novos caminhos nas ciências sociais no Brasil. Tinha sido um pioneiro e grande incentivador do campo da Antropologia Visual. Seu artigo Fotografia e Interdito (Koury, 2004a) foi ousado ao abordar imagens da morte. Sem hesitação, ele conseguia chegar perto da morte e das imagens de corpos mutilados e cadáveres para desconstruí-las: para entender o que o sujeito que produzia a imagem buscava captar e o que aquele que a observava encontrava. Era o jogo de objetivação e subjetivação que se dá naquilo que para Koury (2004b; 2015) era o campo das emoções, tomado como um fato social.

Koury tem o mérito de abordar com muita competência sociológica - e muita delicadeza e respeitoso trato do material de pesquisa - tanto quando trabalha com imagens ou quanto trata, como o fez já no contexto da pandemia, com depoimentos sobre medo, doença e morte (Koury, 2020). Koury (2004b), que sabia como ninguém sobre emoções, munido de teorias, enfrentou com a mesma desenvoltura, temas difíceis como a dor e a morte.

Conhecedor como poucos dos autores interacionistas, conseguia pensar as imagens como construções sociais da realidade, como um processo resultante de relação entre cultura subjetiva e cultura objetiva: 
A fotografia aparece, assim, como uma forma singular de apreensão do real, e seu uso tem um significado variado segundo as formas de assimilação ou os discursos produzidos a partir dos elementos conotados que a constituem. Uma mesma fotografia representa uma infinidade de formas de apreensão e apropriação segundo os usos a que se encontra submetida. Os interditos, quando agem, funcionam sempre em relação aos outros, espaço onde se objetifica o social, embora internamente, na subjetividade da pessoa, possam ser apropriados de forma diferente. (KOURY 2004a, p. 131)

Por que não conversamos mais? Por que não nos lemos mais? Mauro Koury tinha tanto a dizer, tanto ainda a nos ensinar:

Artefato de objetificação do real, a fotografia submete a realidade ao olhar mecânico da máquina e, através dele, parece disciplinar o conjunto de fatos capaz de organizar um discurso sobre o mundo e os homens, ou dos homens e seus mundos e suas relações com a natureza e o sobrenatural. (KOURY 2004a, p. 131).

Nosso texto, como dissemos, se estrutura como uma conversa. Convidamos Mauro Koury a estar presente. Com os comentários acima o fazemos presente nessa narrativa e queremos indicar o seu lugar aqui. Ele é a fala que inicia essa reflexão. Além disso, no que se segue, ele é a terceira vOz nessa interlocução, uma voz sábia que nos dá pistas e nos guia nesse texto que toma a forma de um relato dialógico. Afinal, Koury sempre abraçou o novo, os novos formatos. E também é preciso ser dito: esse texto foi escrito para a Revista Brasileira de Sociologia da Emoção (RBSE), certamente, Mauro Koury está aqui onipresente.

\section{HISTÓRIA DE UMA FOTO}

O presente texto toma a forma de um diálogo entre os autores e enseja estabelecer também uma comunicação dialógica entre as duas sequências de fotos de Achutti. Buscará apresentar os dois conjuntos de imagens, ou as duas narrativas a respeito de formas instituintes que segregam mulheres e a reação e mobilização contra isso, processos que se dão em um intervalo de mais de três décadas, em contextos históricos bastante distintos. Ambos se dão no mesmo cenário, a Casa de Estudantes da UFRGS (CEU) em Porto Alegre. ${ }^{3}$

\footnotetext{
${ }^{3}$ Partes do texto do presente artigo, em outro formato, foram publicadas no semanário Parênteses n53. Porto Alegre, novembro 2020.
} 
Tomamos duas sequencias de fotos de Achutti sobre um mesmo tema, uma delas de 1980 e outra em 2016. Eram histórias através de imagens que se davam com um intervalo de trinta e seis anos. Através de fragmentos de textos e da integridade de imagens reorganizamos memórias e lembramos de uma história de participação feminina, a invasão da casa de estudantes da UFRGS (CEU) pelas mulheres, em 1980. Em 2016, Achutti fotografou outro protesto das mulheres, estudantes, agora moradoras da CEU, denunciando discriminações e violências que sofriam na Casa. São dois momentos históricos, temporalmente distantes um do outro, que ficaram registrados e que através de imagens nos falam de formas de exclusão impostas a mulheres.

Em nossa conversa sobre a exclusão das mulheres e lutas para a superação disso se impôs a foto icônica de Achutti registrando a invasão da casa dos estudantes da UFRGS em abril de 1980. Aquela imagem não dizia mais respeito apenas aquele evento que ocorrera há mais quarenta anos, mas a todas as lutas por acesso a lugares que são vedados a alguns, em geral, aos que não são homens, aos que não são brancos, aos que não são heterossexuais, aos que não são parte da elite ou qualquer outro privilégio que se estabeleça como condição de participação e critério estruturante da vida nossa de cada dia. Mas a foto da Achutti que passou a ser símbolo daquilo que se chamou a invasão das mulheres, em si, em sua muda estética ensurdece com o burburinho da festa, dos sorrisos, da chuva de papéis picados, e da vitória que enuncia: as mulheres entraram! Pequena vitória: no prédio, subiram pelas escadas até o último andar, onde uma assembleia de estudantes iria acontecer. Andar por andar, a multidão de mulheres, que incluía estudantes, mães, irmãs e até avós de moradores da Casa, eram recebidas com salvas de palmas, refrãos e cartazes de boas-vindas. Grande vitória: as mulheres penetraram em um espaço que lhes era negado. Através da imagem escutamos o grito forte, uníssimo e cadenciado daquele dia enquanto subíamos as escadas da CEU: "Mulher não é boneca, mulher não é feijão, mulher luta contra a repressão!"

Imagem testemunho de uma época - do enfrentamento da ditadura e da polícia na rua, e também uma festa de conquista - foi o que nos remeteu à história da foto. Toda imagem trás consigo uma memória:

- Lembro, disse Achutti, que no dia anterior me disseste que no dia seguinte as mulheres iriam invadir a CEU, perguntaste se eu não queria ir para bater umas fotos. Eu tinha vinte e um anos de idade, ainda morando na casa dos pais... eu não sabia de nada, não havia participado de nada. Na época acho que era ator, já nem lembro, se ensaiava ou estava em uma peça em cartaz, estava iniciando o Curso de Ciências Sociais na UFRGS no Campus do Vale e tratando de me dedicar também às minhas fotos. Tinha tido alguma participação no movimento estudantil, quando ocorria algum evento de maior proporção. Não fazia muito, alguns cursos da UFRGS tinham sido deslocados para o Campus do Vale que carecia de infra-estrutrutura e brigávamos pra ter mais 
linhas de ônibus e pelo curso noturno. Criamos o jornalzinho Bandaid Infecto, não é? Fazíamos crítica com bom humor, sem a sisudez dos diretórios acadêmicos. Fazíamos alguma política e muita festa. A política era velada e a festa pública. Queríamos a abertura política, democracia, dar uma basta nos já quase vinte anos de ditadura. A ditadura tinha quase a minha idade. O encontro da “invasão das mulheres” seria no dia seguinte, acho que cedo demais para mim, seria no bar da engenharia para articular os detalhes e pintar cartazes. Fui, estava com muito medo, mas fui.

- Era meu último ano nas Ciências Sociais - disse Ondina -, um grupo de estudantes, mulheres, próximas ao coletivo Liberta, que discutia demandas de emancipação das mulheres, lia Simone de Beauvoir e tinha uma ainda tímida agenda feminista, conclamava a uma manifestação. A UNE, fechada pela ditadura, tentava se reorganizar e promessas de uma abertura política "lenta e gradual" vinham da própria junta militar. 1980 é ano da fundação do PT, eu tinha me mobilizado nesse movimento. Era também o momento do ressurgimento do movimento estudantil e a prioridade dos centros acadêmicos e do DCE era a redemocratização do país. A liderança estudantil, majoritariamente masculina, acreditava que as demandas das mulheres poderiam ser adiadas para depois da reconquista do estado democrático de direito.

Diz Achutti: - Sim, vocês ficaram se organizando no bar e monitorando a presença da Brigada. Quando cheguei, a João Pessoa já estava cheia de brigadianos. Tudo estava coordenado com os guris moradores da Casa. Isso só fui saber muitos anos depois, tanto que naquele dia, foi o efeito da chuva de papéis picados que tanto me surpreendeu: aquilo foi mágico para mim! Eu quis captar aquela imagem. Hora de atravessar a rua e enfrentar a Brigada. Achei que ficaria protegido se ficasse atrás de vocês, atrás das mulheres. Foi o que fiz. Vocês chegaram, carregavam uma grande faixa e entraram na Casa sob os aplausos e papeis picados que vinham das sacadas. Eu fiquei olhando para vocês meio perdido, sem saber o que iria acontecer, quando sobre mim caíam como pétalas os pedacinhos de jornais de todos os tamanhos. Ato reflexo, fui para a borda da calçada e olhei para cima. Putz, como fotografar aquilo com uma lente normal que fechava o quadro no primeiro andar para pegar o todo, porém sem ideia de perspectiva. Solução: tratei de compor a foto na parte de baixo, o primeiro andar do prédio, meu primeiro plano com as pessoas visíveis e a parte de cima da foto coloquei os vários fios elétricos dos postes, no meio e de toda aquela imensidão de chuva de papéis picados de todos os tipos e distâncias o que também lhes davam diferentes tamanhos. Fiz duas ou três fotos: uma torta, outra meia sem foco e uma em que as mãos dos estudantes na sacada estão no primeiro plano à esquerda de quem olha. Depois, ainda temeroso, decidi subir, sabia que todos iriam até o terraço para uma assembleia dos estudantes. Meio fotógrafo egoísta, fui ver os papéis picados do ângulo inverso, todos que estavam no chão e 
que compunham uma espécie de exótico tapete com falhas. Mais duas fotos e fui embora. Eu morava na casa da minha mãe e não tinha o alcance da situação, e temia que a Brigada subisse.

O medo estava lá, junto com a festa. O medo já durava vinte anos. Medo constante que se escondia nas entranhas de nossos corpos, medo de uma ditadura que insistia em mostrar força e violência. A foto, com a chuva de papel picados, guris e gurias nas sacadas do prédio que marcava a conquista da casa de estudantes da UFRGS pelas mulheres, fixou-se na história dos movimentos sociais como um ícone dos anos finais da ditadura em Porto Alegre.

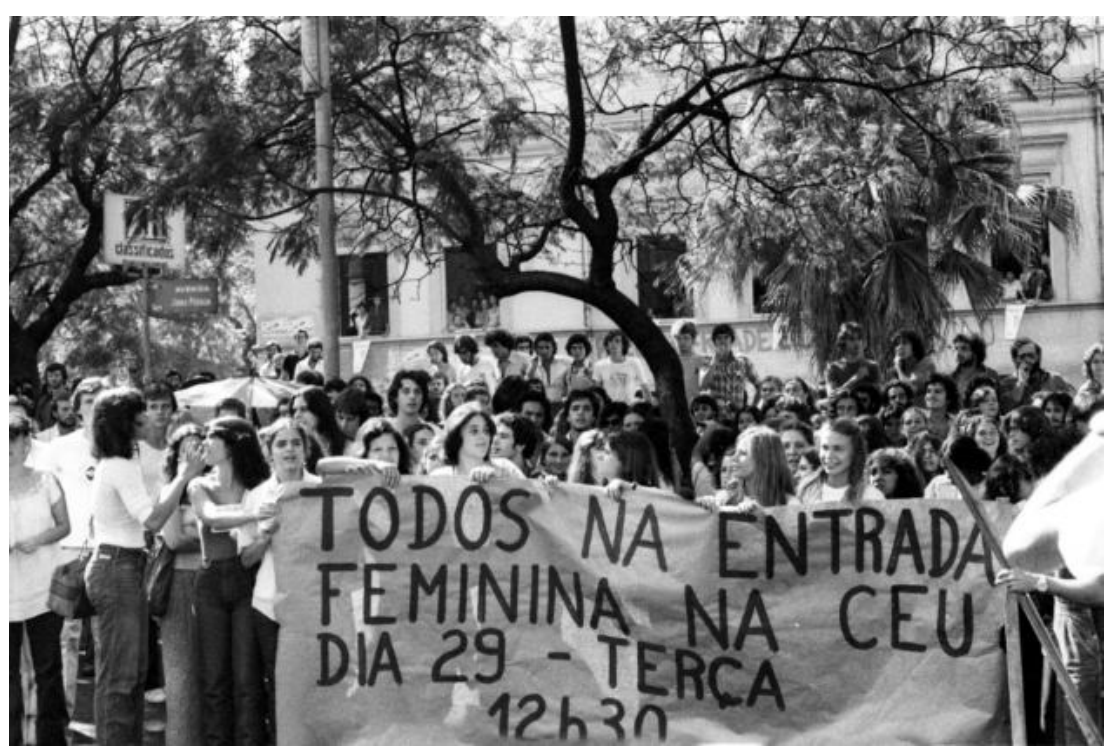

ACHUTTI 1980

Conforme o combinado, naquele dia 21 de abril de 1980, um grupo grande de estudantes se encontrou cedo no bar e no CEUE, o centro acadêmico da Escola de Engenharia para pintar cartazes e organizar a invasão à casa. No dia anterior a UFRGS havia publicado uma "nota à imprensa" no jornal o Correio do Povo, assinada pelo reitor, avisado que não permitiria a entrada de mulheres na casa. A nota era um aviso público da determinação da reitoria de permanecer em sua posição de não permitir a visita de mulheres à CEU, e era o corolário de várias tentativas feitas pela comissão de moradores da CEU para que houvesse mudança do regimento interno da Casa nesse sentido. Mesmo mães, avós, ou irmãs não podiam visitar os moradores, até mesmo na eventualidade de uma enfermidade. A misógina administração da universidade acreditava que a condição feminina trouxesse consigo o sexo, a ameaça, o risco e a desordem. O reitor, Homero Jobim, em reuniões anteriores com a comissão de moradores da casa, tinha sentenciado: "Se quiserem transar vão para a Redenção”, referindo ao parque público em frente à Universidade, como se a presença feminina em si significasse a liberação desenfreada da sexualidade, afinal, na perspectiva daquele senhor, para o que mais poderiam servir as mulheres? 
Depois de repetidas negativas da reitoria para que visitas femininas fossem permitidas onde o reitor reafirmava sua posição autocrática: "enquanto estivesse no cargo não iria permitir que mulheres entrassem na Casa", uma assembleia de moradores da casa, tomou a decisão de que, independente da proibição da reitoria, marcar-se-ia uma visita pública de mulheres à CEU. Um panfleto mimeografado foi amplamente distribuído na universidade e explicava resolução da assembleia dos moradores da Casa, que se posicionava totalmente contrária à decisão da reitoria de manter um regimento arcaico e repressivo que proibia a entrada de mulheres na Casa. O panfleto dizia que os moradores consideravam essa medida "uma visão maniqueísta da mulher: Fala-se em mulher, necessariamente fala-se em cama. Não sabemos o porquê de não termos em nossa própria casa a mesma convivência entre homens e mulheres que, por exemplo, numa sala de aula", e o panfleto era um convite a todas as mulheres para visitar a Casa no dia 29, em uma manifestação de desobediência civil. O texto concluía com três palavras de ordens: "Livre acesso feminino à CEU"; “Contra a discriminação sexual", "Pelo fim da repressão aos moradores". O clima geral no país, no início dos anos 80, era o de dar um basta de ditadura, "Abaixo a repressão" era a palavra de ordem do momento e era o anseio de todos, até mesmo dos liberais de sempre, que tinham até então apoiado e participado da ditadura civil-militar. A história nos mostra que desejos nada liberais ocorrem aos ditos personagens liberais sempre que governos democraticamente eleitos, eventualmente não se coadunavam com suas prioridades e com seus projetos de manutenção de privilégios. 


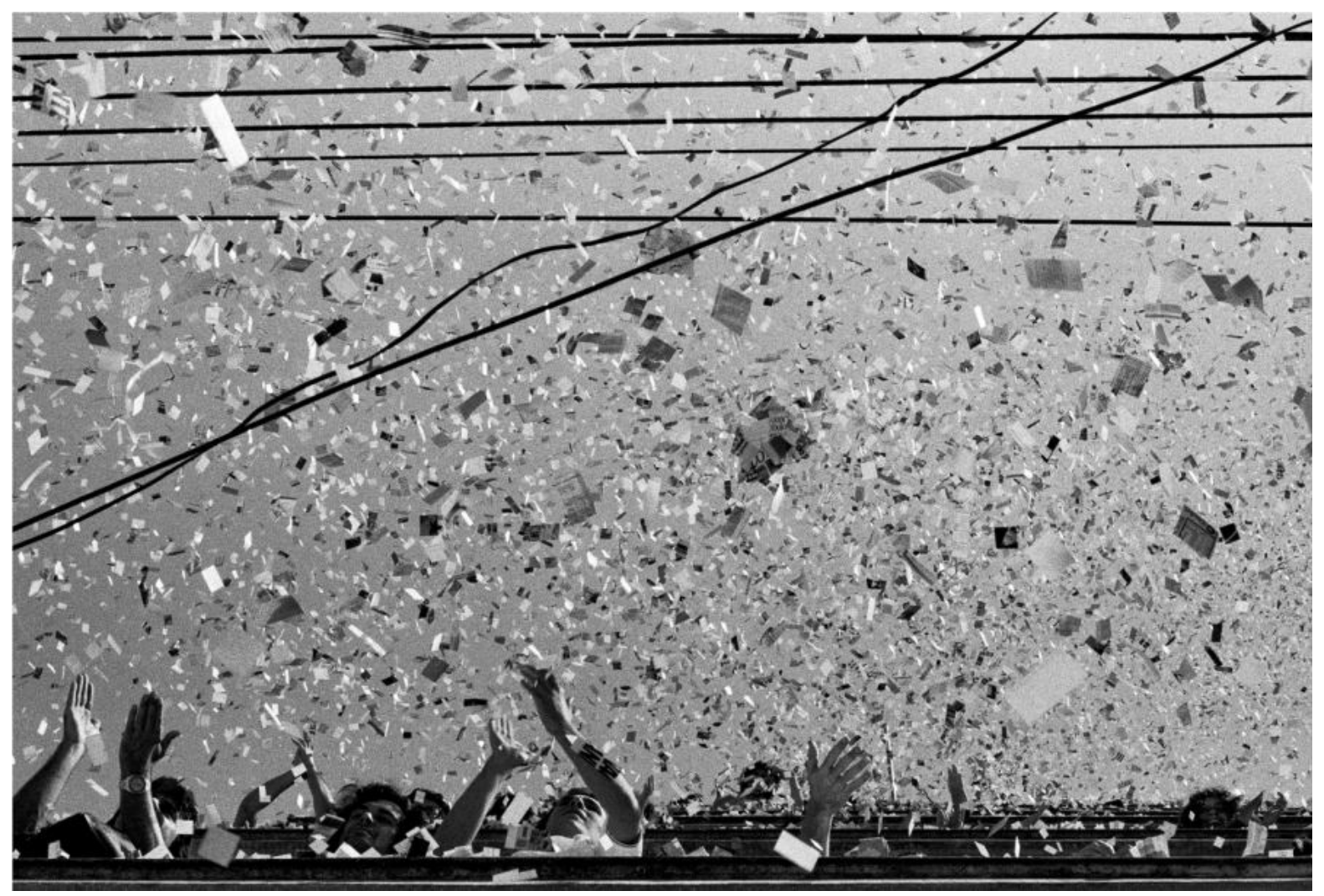

ACHUTTI 1980

Naquele dia de abril de 1980 - o 29 - a casa dos estudantes da UFRGS amanheceu com grandes faixas nas sacadas de cada andar do prédio dando boas-vindas às mulheres. Uma das faixas dizia: “Abram as grades desta prisão". A invasão da casa estava marcada para a hora do almoço, horário que regularmente haveria a concentração dos estudantes na fila do RU que funcionava no andar térreo do prédio. Enquanto isso, desde cedo, no prédio em frente, na Escola de Engenharia, onde funcionava o CEUE, o centro de estudantes de engenharia, um grupo grande de estudantes, sobretudo mulheres, inclusive mães e avós dos moradores que tinham vindo do interior do estado, estavam ocupados pintando faixas e cartazes.

Lembro - diz Ondina - que estava orgulhosa do trocadilho que fiz em um dos cartazes que pintei, onde escrevi “o CEU é também das mulheres". Tão ocupadas e animadas estávamos, que víamos com indiferença a crescente chegada de camburões e a presença da Brigada Militar que ia armando barreiras na movimentada Avenida João Pessoa, que separava o prédio antigo da Engenharia da CEU. A presença dos policiais militares era apenas um detalhe já corriqueiro na paisagem urbana daqueles tempos de repressão e violência. A reitoria ousaria permitir a Brigada dentro do campus da universidade? Como atravessaríamos a rua? A cavalaria da Brigada viria também? Os guris já tinham providenciado as bolinhas de gude? Na mobilização no CEUE a divisão sexual do trabalho era clara: nós, as gurias, pintávamos cartazes e acalmávamos as 
angustiadas e atordoadas mães e avós dos moradores que tinham sido convocadas a vir visitá-los naquele dia. Eles, os guris, martelavam faixas e cartazes e eram responsáveis pela logística e segurança. Para onde correríamos? A casa seria uma grande brete sem saída... Esperávamos o pior, mas há momentos em que enfrentar o pior se faz necessário e a concentração de pessoas no entorno aumentava a cada minuto. Soube-se então que, naquela mesma manhã, no jornal o Correio do Povo, havia saído outra nota do reitor que, distinta da nota do dia anterior, agora dizia que uma visita pública à CEU, permitindo a presença de mulheres, estava sendo oficialmente autorizada durante aquele dia e no dia seguinte. A notícia passava de boca em boca em um rápido zum-zum. Percebeu-se então que a nova nota era uma "manobra da reitoria para esvaziamento da manifestação" e também como uma "vitória das massas" e que a reitoria se rendia ao inevitável.

A multidão, sobretudo mulheres, aglomerava-se no entorno da Escola de Engenharia, no pátio do Faculdade de Direito e em frente à Casa. Uns tinham vindo comovidos pelo direito dos moradores receberem visitas; outros movidos pelos direitos das mulheres em terem as mesmas condições dos estudantes homens e igual direito à moradia estudantil; outros porque não deveria haver espaços em uma universidade pública que excluísse mulheres; outros ainda para soltar aquele grito de "Abaixo a repressão" já contido por tantos anos e para dar um basta ao autoritarismo ou ainda porque era hora do movimento estudantil ter voz... E, muitos e muitas estavam lá por todos esses motivos juntos. Rapidamente pintamos muitos outros cartazes que explicitavam a demanda de acesso permanente das mulheres à casa dos estudantes. Novos cartazes feitos na pressa diziam: “Acesso feminino livre”. Já não se falava mais em visita, mas no direito das estudantes à moradia. “Dois dias?” Perguntava um cartaz. Em outro, grande, lia-se "Dois dias? Livre acesso feminino à CEU". "Direitos iguais: moradia estudantil feminina". Ditos escritos, gritos, palavras de ordem e panfletos foram tomando conta da multidão e daquele espaço, da rua e da Casa. As mulheres que entravam na Casa iam chegando às sacadas do prédio e saudavam a multidão ainda na avenida. A CEU não comportava a multidão que ali estava. Configurou-se uma massa em um número talvez cem vezes maior do que o número de brigadianos ali presentes e, de repente, eles estavam ali segurando o trânsito para nos dar passagem e atravessar a rua. Foi-se o medo, ficou a festa. Dois dias? Viemos para ficar e a os papeis picados e a cidade inteira nos saudavam. Afinal, "mulher não é boneca, mulher não é feijão, mulher luta contra a repressão". 


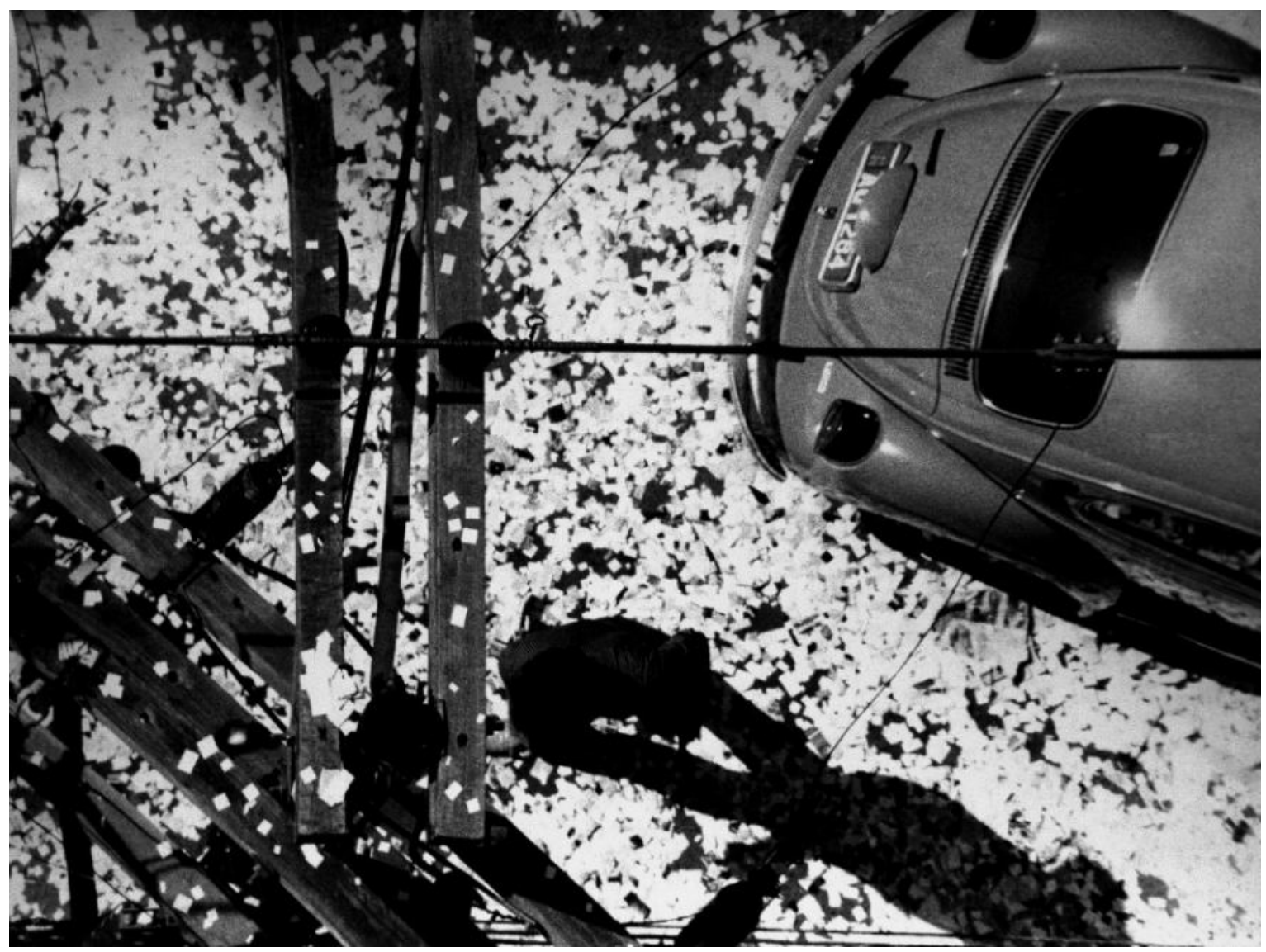

ACHUTTI 1980 


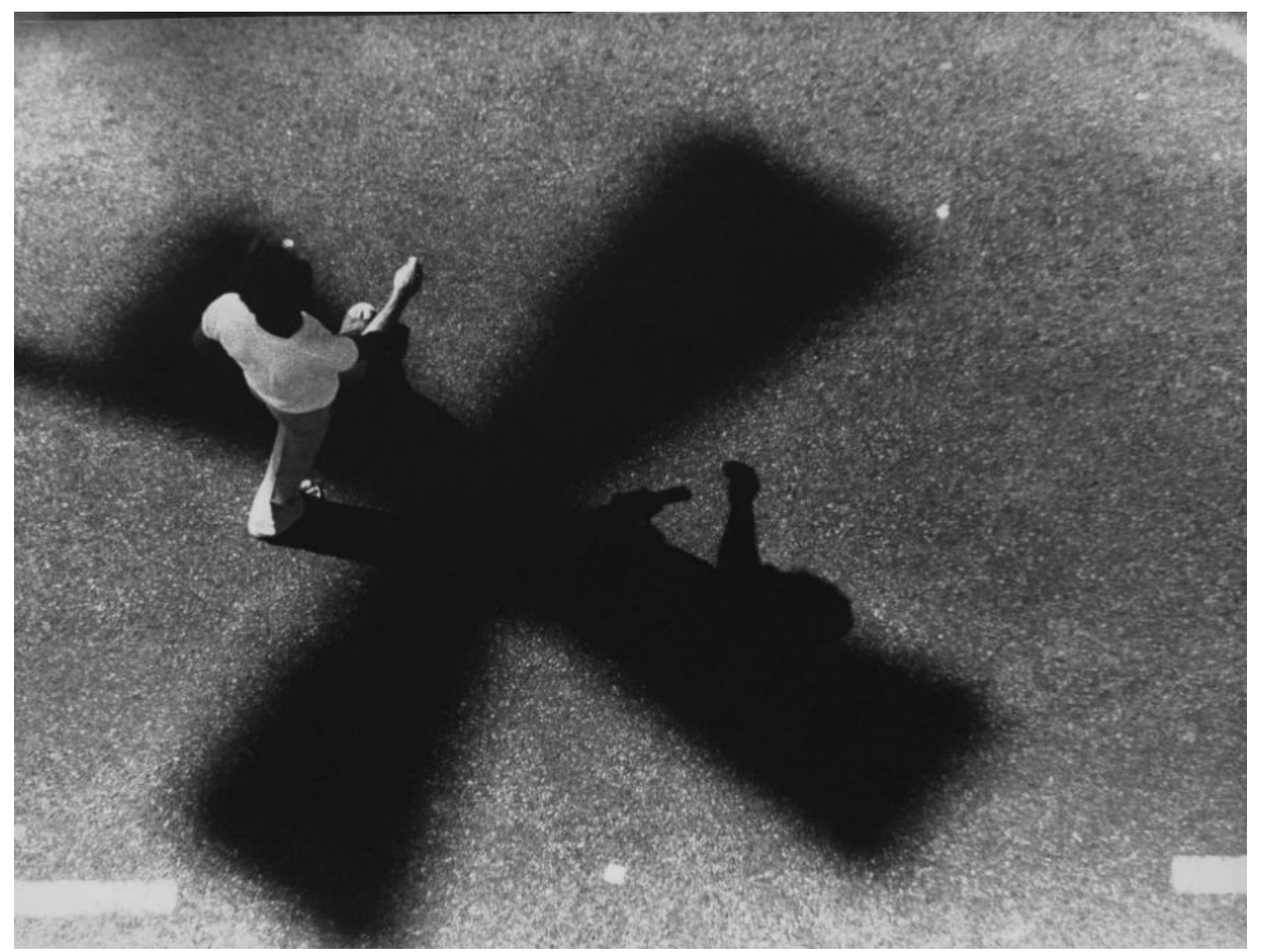

ACHUTTI 1980

As mulheres daquele momento em diante passaram a frequentar a Casa do Estudantes da UFRGS, não muito mais tarde, conseguiram o direito de morar naquela Casa. Muitos anos se passaram, trinta e seis anos. Respirou-se democracia não só na Casa, mas no país.

\section{A OUTRA FOTO}

"Essa fotografia que eu distingo e de que gosto, nada tem a ver com o ponto brilhante que se agita diante dos olhos (...), é antes uma agitação interior, uma festa, também um trabalho, a pressão do indizível que quer ser dito". (Roland Barthes, A Câmara Clara).

Em julho de 2016, estávamos em tempos de preparação das Olimpíadas, era o dia em que a tocha olímpica passaria por Porto Alegre. Os tempos estavam novamente difíceis e um novo golpe político se anunciava contra um governo democraticamente eleito, o da presidente Dilma. O cortejo com a tocha, com a presença presidencial, passaria pela rua João Pessoa em frente a Casa dos Estudantes. Há algum tempo na CEU acumulava-se descontentamentos e reclamações das 
estudantes que ali moravam. Criaram o Coletivo Mulheres da Casa de Estudante e pediam o fim da cultura de segregação e de assédio que era perpetrado por alguns estudantes homens às moradoras da Casa. As estudantes que ali viviam afirmavam sofrer violência verbal e sexual por parte de colegas na residência estudantil e tinham o apoio de alguns estudantes homens em sua luta.

As estudantes, moradoras da Casa, queriam chamar atenção para o problema e que os estudantes que cometiam o abuso fossem responsabilizados e expulsos. A universidade tinha estabelecido comissões de inquérito, mas as estudantes demandavam respostas mais rápidas e efetivas. Queriam pontuar a urgência do problema e certamente, tendo na memoria o movimento das mulheres de 1980, que havia permanecido sobretudo através da imagem de Achutti da festa da invasão com a chuva de papel picado das sacadas do prédio, decidiram usar novamente a própria fachada da casa como o lugar para o grito de denúncia e pedido de ajuda. Queriam que o grito de socorro tivesse visibilidade e se propagasse através da mídia que já estava mobilizada cobrindo o trajeto do cortejo da tocha olímpica.

E aqui queremos refletir sobre a foto de Achutti de 1980, apresentada acima. Mais do que o movimento das mulheres de 1980, a invasão, que instaurou a presença feminina na Casa de estudantes, de fato, a história daquela luta ficou de tal forma mimetizada na foto de Achutti, que passou a fazer parte de nossa memória como o evento. Tanto para aqueles que lá tiveram em 1980, e/ou como imagem-memória para aqueles e aquelas - como era o caso das estudantes que em 2016 buscavam construir sua luta e não eram sequer nascidas na invasão das mulheres, mas tinham a foto de Achutti para contar aquela história e fazer dela sua própria memória. Imagem e memória, confundem-se na fotografia, quando essa tem uma capacidade estética de nos tocar, quando ela é capaz de encantar, quando ela nos tira da indiferença, quando nos conta uma história da qual queremos fazer parte. Como disse Barthes: "Inicialmente para surpreender, a fotografia, para surpreender, fotografa o notável; mas, em breve, por meio de uma reviravolta conhecida, ela decreta que é notável é aquilo que ela fotografa”. (BARTHES, 1981, p. 56).

Para as mulheres, a foto de Achutti da invasão da casa passou a ser emblemática de resistência e superação feminina, para além daquele evento específico de 1980, e permaneceu como testemunho de uma luta, que agora, como evidência histórica se redimensiona. Quando em 2016, o Coletivo de Mulheres da casa de estudante da UFRGS precisa chamar atenção ao seu sofrimento por atos abusivos e fazer um pedido de ajuda, entram em contato com Achutti, convidando-o a fotografar sua mobilização que é um novo grito a respeito da violência e discriminação que vivem no cotidiano da casa. É preciso que o novo evento para dar um basta a isso se repita também através de imagens, pois essas permanecerão. São as imagens da luta, da superação e da festa que criam um vínculo magico entre os dois eventos historicamente separados por décadas. 
A seguir, concluímos, com as imagens do evento de 2016. Distinto de 1980, quando o grito das mulheres vinha de fora da Casa de Estudantes, demandando democracia e o direito de entrar na casa, na sequência de fotos de 2016, o grito vem de dentro da Casa e é um pedido de socorro.

$\mathrm{Na}$ última foto da sequência de 2016, a noite chega, as mulheres que protestavam descem com vassouras, auxiliadas por alguns poucos solidários colegas homens, limpam a rua e recolhem os vestígios de seu protesto. Nessa imagem das mulheres varrendo a rua não há desobediência civil, as mulheres assumem papeis tradicionais e fazendo uso de um instrumento arcaico e mesmo alegórico do feminino, a vassoura. Metaforicamente, a festa acabou. A noite está caindo sobre a era democrática e estamos às vésperas de um novo golpe no país que destituirá o governo eleito. Anuncia-se a chegada de novos tempos sombrios.

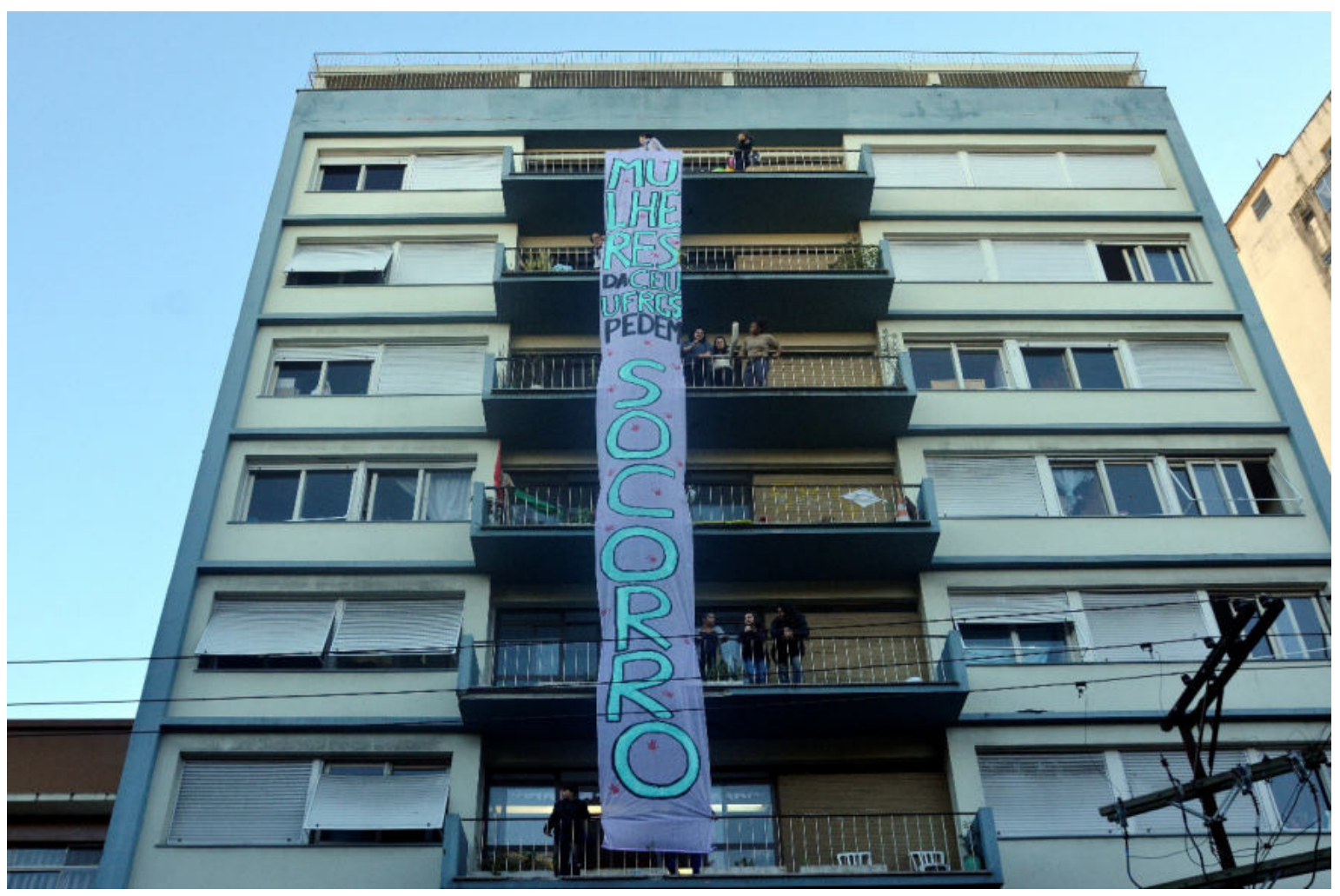

Achutti 2016 

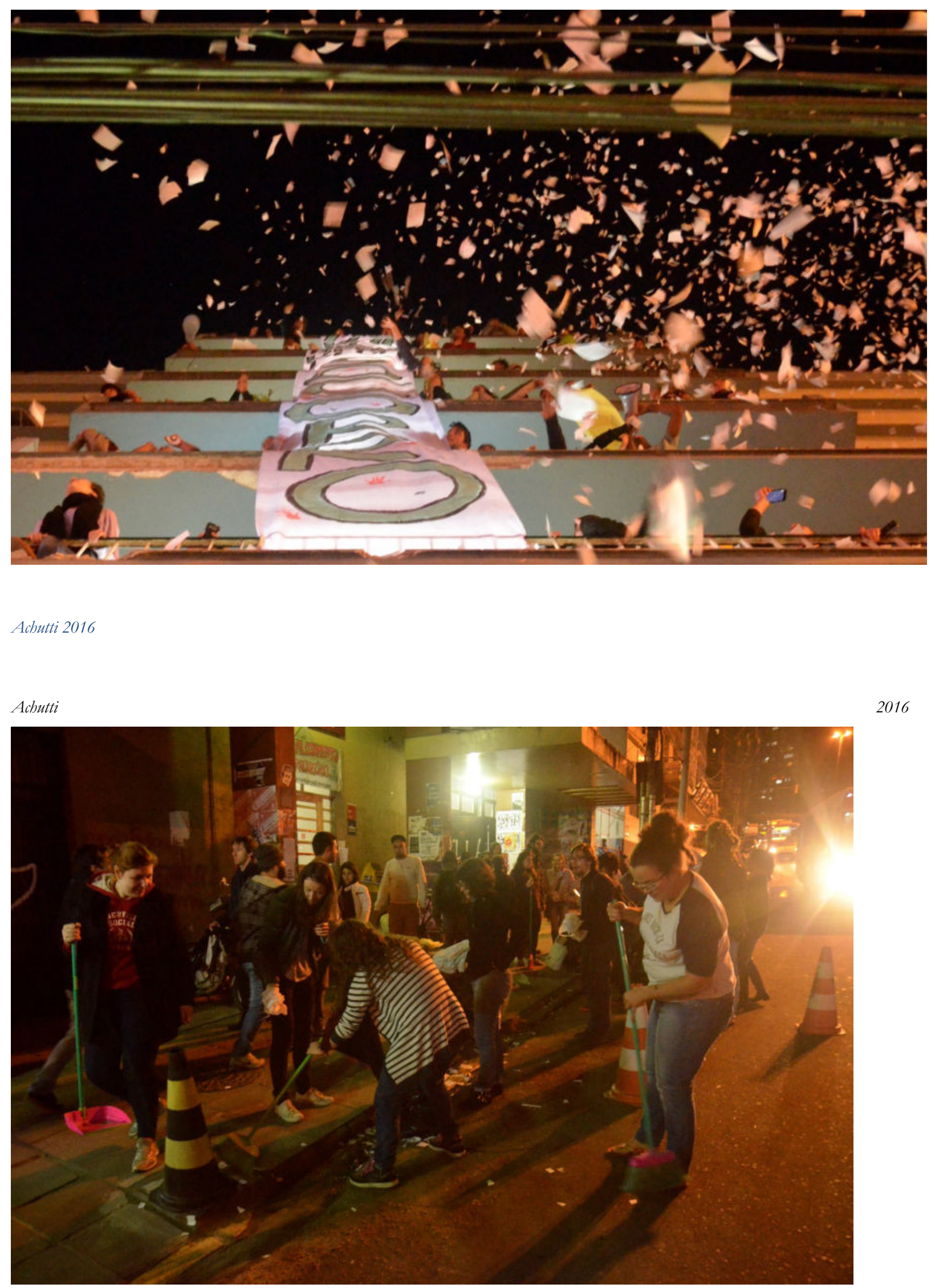
Referências bibliográficas:

BARTHES, Roland. A Câmara Clara. Lisboa: Edições 70, 1981.

KOURY, Mauro Guilherme Pinheiro Fotografia e interdito. RBCS Vol. 19 nº 54 fevereiro, $2004^{a}$

KOURY, Mauro Guilherme. Introdução à sociologia da emoção. João Pessoa: Manufatura, 2004b.

KOURY, Mauro Guilherme Pinheiro; BARBOSA, Raoni Borges. Da subjetividade às emoções: a antropologia e a sociologia das emoções no Brasil. Recife: Edições Bagaço; João Pessoa: Edições GREM, 2015.

KOURY, Mauro Guilherme Pinheiro (org.) Tempos de pandemia: reflexões sobre o caso Brasil. João Pessoa: Grem-Grei; Florianópolis: Tribo da Ilha, 2020. 